\title{
The general iterative methods for equilibrium problems and fixed point problems of a countable family of nonexpansive mappings in Hilbert spaces
}

Kiattisak Rattanaseeha*

"Correspondence:

kiattisakrat@live.com Division of Mathematics,

Department of Science, Faculty of

Science and Technology, Loei

Rajabhat University, Loei, 42000,

Thailand

\begin{abstract}
In this paper, the researcher introduces the general iterative scheme for finding a common element of the set of equilibrium problems and fixed point problems of a countable family of nonexpansive mappings in Hilbert spaces. The results presented in this paper improve and extend the corresponding results announced by many others.

MSC: $47 \mathrm{H} 10 ; 47 \mathrm{H} 09$

Keywords: equilibrium problem; fixed point; nonexpansive mapping; variational inequality; strongly positive operator; Hilbert spaces
\end{abstract}

\section{Introduction}

Let $H$ be a real Hilbert space with the inner product $\langle\cdot, \cdot\rangle$ and the norm $\|\cdot\|$. Let $C$ be a nonempty closed and convex subset of $H$, and let $T: C \rightarrow C$ be a nonlinear mapping. In this paper, we use $F(T)$ to denote the fixed point set of $T$.

Recall the following definitions.

(1) The mapping $T$ is said to be nonexpansive if

$$
\|T x-T y\| \leq\|x-y\|, \quad \forall x, y \in C .
$$

Further, let $F$ be a bifunction from $C \times C$ into $\mathbb{R}$, where $\mathbb{R}$ is the set of real numbers. The so-called equilibrium problem for $F: C \times C \rightarrow \mathbb{R}$ is to find $y \in C$ such that

$$
F(y, u) \geq 0, \quad \forall u \in C
$$

The set of solutions of (1.2) is denoted by $E P(F)$. Given a mapping $A: C \rightarrow H$, let $F(y, u)=$ $\langle A y, u-y\rangle$ for all $y, u \in C$. Then $z \in E P(F)$ if and only if $\langle A z, u-z\rangle \geq 0$ for all $u \in C$. Numerous problems in physics, optimization and economics reduce to finding a solution of (1.2).

(2) The mappings $\left\{T_{n}\right\}_{n \in \mathbb{N}}$ are said to be a family of nonexpansive mappings from $H$ into itself if

$$
\left\|T_{n} x-T_{n} y\right\| \leq\|x-y\|, \quad \forall x, y \in H,
$$

@ 2013 Rattanaseeha; licensee Springer. This is an Open Access article distributed under the terms of the Creative Commons Attribution License (http://creativecommons.org/licenses/by/2.0), which permits unrestricted use, distribution, and reproduction in any medium, provided the original work is properly cited. 
and denoted by $F\left(T_{n}\right)=\left\{x \in H: T_{n} x=x\right\}$ is the fixed point set of $T_{n}$. Finding an optimal point in $\bigcap_{n \in \mathbb{N}} F\left(T_{n}\right)$ of the fixed point sets of each mapping is a matter of interest in various branches of science.

Recently, many authors considered the iterative methods for finding a common element of the set of solutions to problem (1.2) and of the set of fixed points of nonexpansive mappings; see, for example, $[1,2]$ and the references therein.

Next, let $A: C \rightarrow H$ be a nonlinear mapping. We recall the following definitions.

(3) $A$ is said to be monotone if

$$
\langle A x-A y, x-y\rangle \geq 0, \quad \forall x, y \in C .
$$

(4) $A$ is said to be strongly monotone if there exists a constant $\alpha>0$ such that

$$
\langle A x-A y, x-y\rangle \geq \alpha\|x-y\|^{2}, \quad \forall x, y \in C .
$$

In such a case, $A$ is said to be $\alpha$-strongly monotone.

(5) $A$ is said to be inverse-strongly monotone if there exists a constant $\alpha>0$ such that

$$
\langle A x-A y, x-y\rangle \geq \alpha\|A x-A y\|^{2}, \quad \forall x, y \in C .
$$

In such a case, $A$ is said to be $\alpha$-inverse-strongly monotone.

The classical variational inequality is to find $u \in C$ such that

$$
\langle A u, v-u\rangle \geq 0, \quad \forall v \in C .
$$

In this paper, we use $V I(C, A)$ to denote the set of solutions to problem (1.4). One can easily see that the variational inequality problem is equivalent to a fixed point problem. $u \in C$ is a solution to problem (1.4) if and only if $u$ is a fixed point of the mapping $P_{C}(I-\lambda) T$, where $\lambda>0$ is a constant.

The variational inequality has been widely studied in the literature; see, for example, the work of Plubtieng and Punpaeng [3] and the references therein.

Recently, Ceng et al. [4] considered an iterative method for the system of variational inequalities (1.4). They got a strongly convergence theorem for problem (1.4) and a fixed point problem for a single nonexpansive mapping; see [4] for more details.

On the other hand, Moudafi [5] introduced the viscosity approximation method for nonexpansive mappings (see [6] for further developments in both Hilbert and Banach spaces).

A mapping $f: C \rightarrow C$ is called $\alpha$-contractive if there exists a constant $\alpha \in(0,1)$ such that

$$
\|f(x)-f(y)\| \leq \alpha\|x-y\|, \quad \forall x, y \in C .
$$

Let $f$ be a contraction on $C$. Starting with an arbitrary initial $x_{1} \in C$, define a sequence $\left\{x_{n}\right\}$ recursively by

$$
x_{n+1}=\left(1-\sigma_{n}\right) T x_{n}+\sigma_{n} f\left(x_{n}\right), \quad n \geq 0,
$$


where $\left\{\sigma_{n}\right\}$ is a sequence in $(0,1)$. It is proved $[5,6]$ that under certain appropriate conditions imposed on $\left\{\sigma_{n}\right\}$, the sequence $\left\{x_{n}\right\}$ generated by (1.6) strongly converges to the unique solution $q$ in $C$ of the variational inequality

$$
\langle(I-f) q, p-q\rangle \geq 0, \quad p \in C .
$$

Let $A$ be a strongly positive linear bounded operator on a Hilbert space $H$ with a constant $\bar{\gamma}$; that is, there exists $\bar{\gamma}>0$ such that

$$
\langle A x, x\rangle \geq \bar{\gamma}\|x\|^{2}, \quad \forall x \in H
$$

Recently, Marino and Xu [7] introduced the following general iterative method:

$$
x_{n+1}=\left(I-\alpha_{n} A\right) T x_{n}+\alpha_{n} \gamma f\left(x_{n}\right), \quad n \geq 0,
$$

where $A$ is a strongly positive bounded linear operator on $H$. They proved that if the sequence $\left\{\alpha_{n}\right\}$ of parameters satisfies appropriate conditions, then the sequence $\left\{x_{n}\right\}$ generated by (1.8) converges strongly to the unique solution of the variational inequality

$$
\left\langle(A-\gamma f) x^{*}, x-x^{*}\right) \geq 0, \quad x \in C,
$$

which is the optimality condition for the minimization problem

$$
\min _{x \in C} \frac{1}{2}\langle A x, x\rangle-h(x)
$$

where $h$ is a potential function for $\gamma f$ (i.e., $h^{\prime}(x)=\gamma f(x)$ for $x \in H$ ).

In 2007, Takahashi and Takahashi [2] introduced an iterative scheme by the viscosity approximation method for finding a common element of the set of solutions (1.2) and the set of fixed points of a nonexpansive mapping in Hilbert spaces. Let $S: C \rightarrow H$ be a nonexpansive mapping. Starting with arbitrary initial $x_{1} \in H$, define sequences $\left\{x_{n}\right\}$ and $\left\{u_{n}\right\}$ recursively by

$$
\left\{\begin{array}{l}
F\left(u_{n}, y\right)+\frac{1}{r_{n}}\left\langle y-u_{n}, u_{n}-x_{n}\right\rangle \geq 0, \quad \forall y \in C, \\
x_{n+1}=\alpha_{n} \gamma f\left(x_{n}\right)+\left(1-\alpha_{n}\right) S u_{n}, \quad \forall n \in \mathbb{N} .
\end{array}\right.
$$

They proved that under certain appropriate conditions imposed on $\left\{\alpha_{n}\right\}$ and $\left\{r_{n}\right\}$, the sequences $\left\{x_{n}\right\}$ and $\left\{u_{n}\right\}$ converge strongly to $z \in F(S) \cap E P(F)$, where $z=P_{F(S) \cap E P(F)} f(z)$.

Next, Plubtieng and Punpaeng, [3] introduced an iterative scheme by the general iterative method for finding a common element of the set of solutions (1.2) and the set of fixed points of nonexpansive mappings in Hilbert spaces.

Let $S: H \rightarrow H$ be a nonexpansive mapping. Starting with an arbitrary $x_{1} \in H$, define sequences $\left\{x_{n}\right\}$ and $\left\{u_{n}\right\}$ by

$$
\left\{\begin{array}{l}
F\left(u_{n}, y\right)+\frac{1}{r_{n}}\left\langle y-u_{n}, u_{n}-x_{n}\right\rangle \geq 0, \quad \forall y \in C, \\
x_{n+1}=\alpha_{n} \gamma f\left(x_{n}\right)+\left(I-\alpha_{n} A\right) S u_{n}, \quad \forall n \in \mathbb{N} .
\end{array}\right.
$$


They proved that if the sequences $\left\{\alpha_{n}\right\}$ and $\left\{r_{n}\right\}$ of parameters satisfy appropriate conditions, then the sequence $\left\{x_{n}\right\}$ generated by (1.11) converges strongly to the unique solution of the variational inequality

$$
\langle(A-\gamma f) z, x-z) \geq 0, \quad \forall x \in F(S) \cap E P(F)
$$

which is the optimality condition for the minimization problem

$$
\min _{x \in F(S) \cap E P(F)} \frac{1}{2}\langle A x, x\rangle-h(x)
$$

where $h$ is a potential function for $\gamma f$ (i.e., $h^{\prime}(x)=\gamma f(x)$ for $x \in H$ ).

Let $T_{1}, T_{2}, \ldots$ be an infinite sequence of mappings of $C$ into itself, and let $\lambda_{1}, \lambda_{2}, \ldots$ be real numbers such that $0 \leq \lambda_{i} \leq 1$ for every $i \in \mathbb{N}$. Then for any $n \in \mathbb{N}$, Takahashi [8] (see [9]) defined a mapping $W_{n}$ of $C$ into itself as follows:

$$
\begin{aligned}
& U_{n, n+1}=I, \\
& U_{n, n}=\lambda_{n} T_{n} U_{n, n+1}+\left(1-\lambda_{n}\right) I, \\
& U_{n, n-1}=\lambda_{n-1} T_{n-1} U_{n, n}+\left(1-\lambda_{n-1}\right) I, \\
& \vdots \\
& U_{n, k}=\lambda_{k} T_{k} U_{n, k+1}+\left(1-\lambda_{k}\right) I, \\
& U_{n, k-1}=\lambda_{k-1} T_{k-1} U_{n, k}+\left(1-\lambda_{k-1}\right) I, \\
& \vdots \\
& U_{n, 2}=\lambda_{2} T_{2} U_{n, 3}+\left(1-\lambda_{2}\right) I, \\
& W_{n}=U_{n, 1}=\lambda_{1} T_{1} U_{n, 2}+\left(1-\lambda_{1}\right) I .
\end{aligned}
$$

Such a mapping $W_{n}$ is called the $W$-mapping generated by $T_{n}, T_{n-1}, \ldots, T_{1}$ and $\lambda_{n}, \lambda_{n-1}$, $\ldots, \lambda_{1}$.

Recently, using process (1.13), Yao et al. [10] proved the following result.

Theorem 1.1 Let $C$ be a nonempty closed convex subset of a real Hilbert space H. Let $F: C \times C \rightarrow \mathbb{R}$ be an equilibrium bifunction satisfying the conditions:

(1) $F$ is monotone, that is, $F(x, y)+F(y, x) \leq 0$ for all $x, y \in C$;

(2) for each $x, y, z \in C, \lim _{t \rightarrow 0} F(t z+(1-t) x, y) \leq F(x, y)$;

(3) for each $x \in C, y \mapsto F(x, y)$ is convex and lower semicontinuous.

Let $\left\{T_{i}\right\}_{i=1}^{\infty}$ be an infinite family of nonexpansive mappings of $C$ into $C$ such that $\bigcap_{i=1}^{\infty} F\left(T_{i}\right) \cap E P(F) \neq \emptyset$. Suppose $\left\{\alpha_{n}\right\},\left\{\beta_{n}\right\}$ and $\left\{\gamma_{n}\right\}$ are three sequences in $(0,1)$ such that $\alpha_{n}+\beta_{n}+\gamma_{n}=1$ and $\left\{r_{n}\right\} \subset(0, \infty)$. Suppose the following conditions are satisfied:

(1) $\lim _{n \rightarrow \infty} \alpha_{n}=0$ and $\sum_{n=1}^{\infty} \alpha_{n}=\infty$;

(2) $0<\liminf _{n \rightarrow \infty} \beta_{n} \leq \lim \sup _{n \rightarrow \infty} \beta_{n}<1$;

(3) $\liminf _{n \rightarrow \infty} r_{n}>0$ and $\lim _{n \rightarrow \infty}\left(r_{n+1}-r_{n}\right)=0$. 
Letf be a contraction of $H$ into itself, and let $x_{0} \in H$ be given arbitrarily. Then the sequences $\left\{x_{n}\right\}$ and $\left\{y_{n}\right\}$ generated iteratively by

$$
\left\{\begin{array}{l}
F\left(y_{n}, x\right)+\frac{1}{r_{n}}\left\langle x-y_{n}, y_{n}-x_{n}\right\rangle \geq 0, \quad \forall x \in C, \\
x_{n+1}=\alpha_{n} f\left(x_{n}\right)+\beta_{n} x_{n}+\gamma_{n} W_{n} y_{n},
\end{array}\right.
$$

converge strongly to $x^{*} \in \bigcap_{i=1}^{\infty} F\left(T_{i}\right) \cap E P(F)$, the unique solution of the minimization problem

$$
\min _{x \in \bigcap_{i=1}^{\infty} F\left(T_{i}\right) \cap E P(F)} \frac{1}{2}\|x\|^{2}-h(x),
$$

where $h$ is a potential function for $f$.

Very recently, using process (1.13), Chen [11] proved the following result.

Theorem 1.2 Let $C$ be a nonempty closed convex subset of a real Hilbert space H. Let $\left\{T_{n}\right\}_{n=1}^{\infty}$ be a sequence of nonexpansive mappings from $C$ to $C$ such that the common fixed point set $\Omega=\bigcap_{n=1}^{\infty} F\left(T_{n}\right) \neq \emptyset$. Let $f: C \rightarrow H$ be an $\alpha$-contraction, and let $A: H \rightarrow H$ be a self-adjoint, strongly positive bounded linear operator with a coefficient $\bar{\gamma}>0$. Let $\sigma$ be a constant such that $0<\gamma \alpha<\bar{\gamma}$. For an arbitrary initial point $x_{0}$ belonging to $C$, one defines a sequence $\left\{x_{n}\right\}_{n \geq 0}$ iteratively

$$
x_{n+1}=P_{C}\left[\alpha_{n} \gamma f\left(x_{n}\right)+\left(I-\alpha_{n} A\right) W_{n} x_{n}\right], \quad \forall n \geq 0,
$$

where $\left\{\alpha_{n}\right\}$ is a real sequence in $[0,1]$. Assume the sequence $\left\{\alpha_{n}\right\}$ satisfies the following conditions:

(C1) $\lim _{n \rightarrow \infty} \alpha_{n}=0$;

(C2) $\sum_{n=1}^{\infty} \alpha_{n}=\infty$.

Then the sequence $\left\{x_{n}\right\}$ generated by (1.14) converges in norm to the unique solution $x^{*}$, which solves the following variational inequality:

$$
x^{*} \in \Omega \text { such that }\left\langle(A-\gamma f) x^{*}, x^{*}-\hat{x}\right\rangle \geq 0, \forall \hat{x} \in \Omega \text {. }
$$

Motivated by this result, we introduce the following explicit general iterative scheme:

$$
\left\{\begin{array}{l}
x_{1} \in H, \\
F\left(u_{n}, y\right)+\frac{1}{r_{n}}\left\langle y-u_{n}, u_{n}-x_{n}\right\rangle \geq 0, \quad \forall y \in H, \\
x_{n+1}=P_{C}\left[\alpha_{n} \gamma f\left(x_{n}\right)+\left(I-\alpha_{n} A\right) W_{n} u_{n}\right], \quad \forall n \in \mathbb{N},
\end{array}\right.
$$

where $\left\{T_{n}\right\}_{n \in \mathbb{N}}$ is a family of nonexpansive mappings from $H$ into itself such that $\bigcap_{n \in \mathbb{N}} F\left(T_{n}\right)$ is nonempty, $F: C \times C \rightarrow \mathbb{R}$ is an equilibrium bifunction, $A$ is a strongly positive operator on $H, f$ is a contraction of $H$ into itself with $\alpha \in(0,1),\left\{\alpha_{n}\right\},\left\{r_{n}\right\},\left\{\lambda_{n}\right\}$ suitable sequences in $\mathbb{R}$ and $\left\{W_{n}\right\}$ is the sequence of a $W$-mapping generated by $\left\{T_{n}\right\}_{n \in \mathbb{N}}$ and $\left\{\lambda_{n}\right\}$. Let $U$ be defined by $U x=\lim _{n \rightarrow \infty} W_{n} x=\lim _{n \rightarrow \infty} U_{n, 1} x$ for every $x \in C$ using process (1.13). We shall prove under mild conditions that $\left\{x_{n}\right\}$ and $\left\{u_{n}\right\}$ strongly converge to 
a point $x^{*} \in \bigcap_{i=1}^{\infty} F\left(T_{i}\right) \cap E P(F)$, which is the unique solution of the variational inequality

$$
\left\langle(A-\gamma f) x^{*}, x^{*}-\hat{x}\right\rangle \geq 0, \quad \forall \hat{x} \in \bigcap_{i=1}^{\infty} F\left(T_{i}\right) \cap E P(F)
$$

or, equivalently, the unique solution of the minimization problem

$$
\min _{x \in \bigcap_{i=1}^{\infty} F\left(T_{i}\right) \cap E P(F)} \frac{1}{2}\langle A \hat{x}, \hat{x}\rangle-h(\hat{x}),
$$

where $h$ is a potential function for $\gamma f$.

\section{Preliminaries}

Let $H$ be a real Hilbert space with the norm $\|\cdot\|$ and the inner product $\langle\cdot, \cdot\rangle$, and let $C$ be a closed convex subset of $H$. We call $f: C \rightarrow H$ an $\alpha$-contraction if there exists a constant $\alpha \in[0,1)$ such that

$$
\|f(x)-f(y)\| \leq \alpha\|x-y\|, \quad \forall x, y \in C
$$

Let $A$ be a strongly positive linear bounded operator on a Hilbert space $H$ with a constant $\bar{\gamma}$; that is, there exists $\bar{\gamma}>0$ such that

$$
\langle A x, x\rangle \geq \bar{\gamma}\|x\|^{2}, \quad \forall x \in H .
$$

Next, we denote weak convergence and strong convergence by notations $\rightarrow$ and $\rightarrow$, respectively. A space $X$ is said to satisfy Opial's condition [12] if for each sequence $\left\{x_{n}\right\}$ in $X$ which converges weakly to a point $x \in X$, we have

$$
\liminf _{n \rightarrow \infty}\left\|x_{n}-x\right\|<\liminf _{n \rightarrow \infty}\left\|x_{n}-y\right\|, \quad \forall y \in X, y \neq x
$$

For every point $x \in H$, there exists a unique nearest point in $C$, denoted by $P_{C} x$, such that

$$
\left\|x-P_{C} x\right\| \leq\|x-y\|, \quad \forall y \in C .
$$

$P_{C}$ is called the (nearest point or metric) projection of $H$ onto $C$. In addition, $P_{C} x$ is characterized by the following properties: $P_{C} x \in C$ and

$$
\begin{aligned}
& \left\langle x-P_{C} x, y-P_{C} x\right\rangle \geq 0, \\
& \|x-y\|^{2} \geq\left\|x-P_{C} x\right\|^{2}+\left\|y-P_{C} x\right\|^{2}, \quad \forall x \in H, y \in C .
\end{aligned}
$$

Recall that a mapping $T: H \rightarrow H$ is said to be firmly nonexpansive mapping if

$$
\|T x-T y\|^{2} \leq\langle T x-T y, x-y\rangle, \quad \forall x, y \in H .
$$

It is well known that $P_{C}$ is a firmly nonexpansive mapping of $H$ onto $C$ and satisfies

$$
\left\|P_{C} x-P_{C} y\right\|^{2} \leq\left\langle x-y, P_{C} x-P_{C} y\right\rangle, \quad \forall x, y \in H .
$$


If $A$ is an $\alpha$-inverse-strongly monotone mapping of $C$ into $H$, then it is obvious that $A$ is $\frac{1}{\alpha}$-Lipschitz continuous. We also have that for all $x, y \in C$ and $\lambda>0$,

$$
\begin{aligned}
\|(I-\lambda A) x-(I-\lambda A) y\|^{2} & =\|x-y-\lambda(A x-A y)\|^{2} \\
& =\|x-y\|^{2}-2 \lambda\langle A x-A y, x-y\rangle+\lambda^{2}\|A x-A y\|^{2} \\
& \leq\|x-y\|^{2}+\lambda(\lambda-2 \alpha)\|A x-A y\|^{2} .
\end{aligned}
$$

So, if $\lambda \leq 2 \alpha$, then $I-\lambda A$ is a nonexpansive mapping of $C$ into $H$.

The following lemmas will be useful for proving the convergence result of this paper.

Lemma 2.1 Let $H$ be a real Hilbert space. Then for all $x, y \in H$,

(1) $\|x+y\|^{2} \leq\|x\|^{2}+2\langle y, x+y\rangle$;

(2) $\|x+y\|^{2} \geq\|x\|^{2}+2\langle y, x\rangle$.

Lemma 2.2 ([13]) Let $\left\{x_{n}\right\}$ and $\left\{y_{n}\right\}$ be bounded sequences in a Banach space $X$, and let $\left\{\beta_{n}\right\}$ be a sequence in $[0,1]$ with $0<\liminf _{n \rightarrow \infty} \beta_{n} \leq \limsup _{n \rightarrow \infty} \beta_{n}<1$. Suppose that $x_{n+1}=$ $\left(1-\beta_{n}\right) y_{n}+\beta_{n} x_{n}$ for all integers $n \geq 0$ and $\limsup _{n \rightarrow \infty}\left(\left\|y_{n+1}-y_{n}\right\|-\left\|x_{n+1}-x_{n}\right\|\right) \leq 0$. Then $\lim _{n \rightarrow \infty}\left\|y_{n}-x_{n}\right\|=0$.

Lemma 2.3 ([14]) Assume that $F: C \times C \rightarrow \mathbb{R}$, let us assume that $F$ satisfies the following conditions:

(A1) $F(x, x)=0$ for all $x \in C$;

(A2) $F$ is monotone, i.e., $F(x, y)+F(y, x) \leq 0$ for all $x, y \in C$;

(A3) for each $x, y, z \in C, \lim _{t \rightarrow 0} F(t z+(1-t) x, y) \leq F(x, y)$;

(A4) for each $x \in C, y \mapsto F(x, y)$ is convex and lower semicontinuous.

Lemma 2.4 ([14]) Assume that $F: C \times C \rightarrow \mathbb{R}$ satisfies (A1)-(A4). For $r>0$ and $x \in H$, define a mapping $T_{r}: H \rightarrow C$ as follows:

$$
T_{r}(x)=\left\{z \in C: F(z, y)+\frac{1}{r}\langle y-z, z-x\rangle \geq 0, \forall y \in C\right\}
$$

for all $z \in H$. Then the following hold:

1. $T_{r}$ is single-valued;

2. $T_{r}$ is firmly nonexpansive, i.e., for any $x, y \in H$,

$$
\left\|T_{r} x-T_{r} y\right\|^{2} \leq\left\langle T_{r} x-T_{r} y, x-y\right\rangle
$$

3. $F\left(T_{r}\right)=E P(F)$;

4. $E P(F)$ is closed and convex.

Lemma 2.5 ([12]) Let $H$ be a Hilbert space, $C$ be a closed convex subset of $H$, and $S: C \rightarrow C$ be a nonexpansive mapping with $F(S) \neq \emptyset$. If $\left\{x_{n}\right\}$ is a sequence in $C$ weakly converging to $x \in C$ and if $\left\{(I-S) x_{n}\right\}$ converges strongly to $y$, then $(I-S) x=y$.

Lemma 2.6 ([6]) Assume that $\left\{a_{n}\right\}$ is a sequence of nonnegative real numbers such that

$$
a_{n+1} \leq\left(1-\gamma_{n}\right) a_{n}+\delta_{n}, \quad n \geq 0,
$$


where $\left\{\gamma_{n}\right\}$ is a sequence in $(0,1)$ and $\left\{\delta_{n}\right\}$ is a sequence in $\mathbb{R}$ such that

(1) $\sum_{n=1}^{\infty} \gamma_{n}=\infty$;

(2) $\lim \sup _{n \rightarrow \infty} \frac{\delta_{n}}{\gamma_{n}} \leq 0$ or $\sum_{n=1}^{\infty}\left|\delta_{n}\right|<\infty$.

Then $\lim _{n \rightarrow \infty} a_{n}=0$.

Lemma 2.7 ([7]) Let $H$ be a Hilbert space, $C$ be a nonempty closed convex subset of $H$, and $f: H \rightarrow H$ be a contraction with a coefficient $0<\alpha<1$, and let $A$ be a strongly positive linear bounded operator with a coefficient $\bar{\gamma}>0$. Then, for $0<\gamma<\frac{\bar{\gamma}}{\alpha}$,

$$
\langle x-y,(A-\gamma f) x-(A-\gamma f) y\rangle \geq(\bar{\gamma}-\gamma \alpha)\|x-y\|^{2}, \quad x, y \in H .
$$

That is, $A-\gamma f$ is strongly monotone with a coefficient $\bar{\gamma}-\gamma \alpha$.

Lemma 2.8 ([7]) Assume $A$ is a strongly positive linear bounded operator on a Hilbert space $H$ with a coefficient $\bar{\gamma}>0$ and $0<\rho \leq\|A\|^{-1}$. Then $\|I-\rho A\| \leq 1-\rho \bar{\gamma}$.

Lemma 2.9 ([9] and [15]) Let C be a nonempty closed convex subset of a Banach space $E$. Let $\left\{T_{i}\right\}_{i=1}^{\infty}$ be a sequence of nonexpansive mappings of $C$ into itself with $\bigcap_{i=1}^{\infty} F\left(T_{i}\right) \neq \emptyset$, and let $\left\{\lambda_{i}\right\}_{i=1}^{\infty}$ be a real sequence such that $0<\lambda_{i} \leq b<1, \forall i \geq 1$. Then:

(1) $W_{n}$ is nonexpansive and $F\left(W_{n}\right)=\bigcap_{i=1}^{\infty} F\left(T_{i}\right)$ for each $n \geq 1$;

(2) for each $x \in C$ and for each positive integer $k$, the $\lim _{n \rightarrow \infty} U_{n, k} x$ exists;

(3) the mapping $U: C \rightarrow C$ defined by

$$
U x=\lim _{n \rightarrow \infty} W_{n} x=\lim _{n \rightarrow \infty} U_{n, 1} x, \quad x \in C
$$

is a nonexpansive mapping satisfying $F(U)=\bigcap_{n=1}^{\infty} F\left(T_{i}\right)$ and it is called the $W$-mapping generated by $T_{1}, T_{2}, \ldots$ and $\lambda_{1}, \lambda_{2}, \ldots$;

(4) $\lim _{m, n \rightarrow \infty} \sup _{x \in K}\left\|W_{m} x-W_{n} x\right\|=0$ for any bounded subset $K$ of $E$.

\section{Main results}

In this section, we introduce our algorithm and prove its strong convergence.

Theorem 3.1 Let $C$ be a closed convex subset of a real Hilbert space H. Let F be a bifunction from $H \times H$ into $\mathbb{R}$ satisfying (A1)-(A4). Let $f$ be a contraction of $H$ into itself with $\alpha \in$ $(0,1)$, and let $T_{n}$ be a sequence of nonexpansive mappings of $C$ into itself such that $\Omega=$ $\bigcap_{n=1}^{\infty} F\left(T_{n}\right) \cap E P(F) \neq \emptyset$. Let $A: H \rightarrow H$ be a strongly positive bounded linear operator with a coefficient $\bar{\gamma}>0$ with $0<\gamma<\frac{\bar{\gamma}}{\alpha}$. Let $\lambda_{1}, \lambda_{2}, \ldots$ be a sequence of real numbers such that $0<\lambda_{n} \leq b<1$ for every $n=1,2, \ldots$. Let $W_{n}$ be a $W$-mapping of $C$ into itself generated by $T_{n}, T_{n-1}, \ldots, T_{1}$ and $\lambda_{n}, \lambda_{n-1}, \ldots, \lambda_{1}$. Let $U$ be defined by $U x=\lim _{n \rightarrow \infty} W_{n} x=\lim _{n \rightarrow \infty} U_{n, 1} x$ for every $x \in C$. Let $\left\{x_{n}\right\}$ and $\left\{u_{n}\right\}$ be sequences generated by $x_{1} \in H$ and

$$
\left\{\begin{array}{l}
F\left(u_{n}, y\right)+\frac{1}{r_{n}}\left\langle y-u_{n}, u_{n}-x_{n}\right\rangle \geq 0, \quad \forall y \in H, \\
x_{n+1}=P_{C}\left[\alpha_{n} \gamma f\left(x_{n}\right)+\left(I-\alpha_{n} A\right) W_{n} u_{n}\right], \quad \forall n \in \mathbb{N}
\end{array}\right.
$$

where $\left\{\alpha_{n}\right\}$ is a sequence in $(0,1)$ and $\left\{r_{n}\right\}$ is a sequence in $[0, \infty)$. Suppose that $\left\{\alpha_{n}\right\}$ and $\left\{r_{n}\right\}$ satisfy the following conditions: 
(C1) $\lim _{n \rightarrow \infty} \alpha_{n}=0$;

(C2) $\sum_{n=1}^{\infty} \alpha_{n}=\infty$;

(C3) $\lim _{n \rightarrow \infty} r_{n}=r>0$.

Then both $\left\{x_{n}\right\}$ and $\left\{u_{n}\right\}$ converge strongly to $x^{*} \in \Omega$, which is the unique solution of the variational inequality

$$
\left\langle(A-\gamma f) x^{*}, x^{*}-\hat{x}\right\rangle \geq 0, \quad \forall \hat{x} \in \Omega
$$

Equivalently, one has $x^{*}=P_{\Omega}(I-A+\gamma f)\left(x^{*}\right)$.

Proof We observe that $P_{\Omega}(\gamma f+(I-A))$ is a contraction. Indeed, for all $x, y \in H$, we have

$$
\begin{aligned}
\left\|P_{\Omega}(\gamma f+(I-A))(x)-P_{\Omega}(\gamma f+(I-A))(y)\right\| & \leq\|(\gamma f+(I-A))(x)-(\gamma f+(I-A))(y)\| \\
& \leq \gamma\|f(x)-f(y)\|+\|I-A\|\|x-y\| \\
& \leq \gamma \alpha\|x-y\|+(1-\bar{\gamma})\|x-y\| \\
& <(1-(\bar{\gamma}-\gamma \alpha))\|x-y\| .
\end{aligned}
$$

Banach's contraction mapping principle guarantees that $P_{\Omega}(\gamma f+(I-A))$ has a unique fixed point, say $x^{*} \in H$. That is, $x^{*}=P_{\Omega}(\gamma f+(I-A))\left(x^{*}\right)$. Note that by Lemma 2.4 , we can write

$$
x_{n+1}=P_{C}\left[\alpha_{n} \gamma f\left(x_{n}\right)+\left(I-\alpha_{n} A\right) W_{n} T_{r_{n}} x_{n}\right] \text {, }
$$

where

$$
T_{r_{n}}(x)=\left\{z \in H: F(z, y)+\frac{1}{r_{n}}\langle y-z, z-x\rangle \geq 0, \forall y \in H\right\} .
$$

Moreover, since $\alpha_{n} \rightarrow 0$ as $n \rightarrow \infty$ by condition (C1), we assume that $\alpha_{n} \leq\|A\|^{-1}$ for all $n \in \mathbb{N}$. From Lemma 2.8, we know that if $0<\rho<\|A\|^{-1}$, then $\|I-\rho A\| \leq 1-\rho \bar{\gamma}$. We divide the proof into seven steps as follows.

Step 1 . Show that the sequences $\left\{x_{n}\right\}$ and $\left\{u_{n}\right\}$ are bounded.

Let $\hat{x} \in \Omega$. Then $\hat{x} \in E P(F)$. From Lemma 2.4, we have

$$
\left\|u_{n}-\hat{x}\right\|=\left\|T_{r_{n}} x_{n}-T_{r_{n}} \hat{x}\right\| \leq\left\|x_{n}-\hat{x}\right\| .
$$

Thus, we have

$$
\begin{aligned}
\left\|x_{n+1}-\hat{x}\right\| & =\left\|P_{C}\left[\alpha_{n} \gamma f\left(x_{n}\right)+\left(I-\alpha_{n} A\right) W_{n} u_{n}\right]-\hat{x}\right\| \\
& \leq\left\|\alpha_{n} \gamma f\left(x_{n}\right)+\left(I-\alpha_{n} A\right) W_{n} u_{n}-\hat{x}\right\| \\
& \leq \alpha_{n} \gamma\left\|f\left(x_{n}\right)-f(\hat{x})\right\|+\left\|I-\alpha_{n} A\right\|\left\|W_{n} u_{n}-\hat{x}\right\|+\alpha_{n}\|\gamma f(\hat{x})-A \hat{x}\| \\
& \leq \alpha_{n} \gamma \alpha\left\|x_{n}-\hat{x}\right\|+\left(1-\alpha_{n} \bar{\gamma}\right)\left\|u_{n}-\hat{x}\right\|+\alpha_{n}\|\gamma f(\hat{x})-A \hat{x}\| \\
& =\left(1-\alpha_{n}(\bar{\gamma}-\gamma \alpha)\right)\left\|x_{n}-\hat{x}\right\|+\alpha_{n}(\bar{\gamma}-\gamma \alpha) \frac{\|\gamma f(\hat{x})-A \hat{x}\|}{(\bar{\gamma}-\gamma \alpha)} .
\end{aligned}
$$


By induction, we have

$$
\left\|x_{n}-\hat{x}\right\| \leq \max \left\{\left\|x_{1}-\hat{x}\right\|, \frac{\|\gamma f(\hat{x})-A \hat{x}\|}{\bar{\gamma}-\gamma \alpha}\right\}, \quad \forall n \geq 0 .
$$

This shows that the sequence $\left\{x_{n}\right\}$ is bounded, so are $\left\{u_{n}\right\},\left\{f\left(x_{n}\right)\right\}$ and $\left\{W_{n} u_{n}\right\}$.

Step 2. Show that $\left\|W_{n+1} u_{n}-W_{n} u_{n}\right\| \rightarrow 0$ as $n \rightarrow \infty$.

Let $\hat{x} \in \Omega$. Since $T_{i}$ and $U_{n, i}$ are nonexpansive and $T_{i} \hat{x}=\hat{x}=U_{n, i} \hat{x}$ for every $n \in \mathbb{N}$ and $i \leq n+1$, it follows that

$$
\begin{aligned}
\left\|W_{n+1} u_{n}-W_{n} u_{n}\right\| & =\left\|\lambda_{1} T_{1} U_{n+1,2} u_{n}-\lambda_{1} T_{1} U_{n, 2} u_{n}\right\| \\
& \leq \lambda_{1}\left\|U_{n+1,2} u_{n}-U_{n, 2} u_{n}\right\| \\
& =\lambda_{1}\left\|\lambda_{2} T_{2} U_{n+1,3} u_{n}-\lambda_{2} T_{2} U_{n, 3} u_{n}\right\| \\
& \leq \lambda_{1} \lambda_{2}\left\|U_{n+1,3} u_{n}-U_{n, 3} u_{n}\right\| \\
& \vdots \\
& \leq\left(\prod_{i=1}^{n} \lambda_{i}\right)\left\|U_{n+1, n+1} u_{n}-\hat{x}+\hat{x}-U_{n, n+1} u_{n}\right\| \\
& \leq\left(\prod_{i=1}^{n} \lambda_{i}\right)\left(\left\|U_{n+1, n+1} u_{n}-\hat{x}+\hat{x}-U_{n, n+1} u_{n}\right\|\right) \\
& \leq 2\left(\prod_{i=1}^{n} \lambda_{i}\right)\left\|u_{n}-\hat{x}\right\| .
\end{aligned}
$$

Since $\left\{u_{n}\right\}$ is bounded and $0<\lambda_{n} \leq b<1$ for any $n \in \mathbb{N}$, the following holds:

$$
\lim _{n \rightarrow \infty}\left\|W_{n+1} u_{n}-W_{n} u_{n}\right\|=0 .
$$

Step 3. Show that $\left\|x_{n+1}-x_{n}\right\| \rightarrow 0$ as $n \rightarrow \infty$.

Setting $S=2 P_{C}-I$, we have $S$ is nonexpansive. Note that $W_{n}=\left(1-\lambda_{1}\right) I+\lambda_{1} T_{1} U_{n, 2}$. Then we can write

$$
\begin{aligned}
x_{n+1}= & \frac{I+S}{2}\left[\alpha_{n} \gamma f\left(x_{n}\right)+\left(I-\alpha_{n} A\right) W_{n} u_{n}\right] \\
= & \frac{1-\alpha_{n}}{2} W_{n} u_{n}+\frac{\alpha_{n}}{2}\left(\gamma f\left(x_{n}\right)-A W_{n} u_{n}+W_{n} u_{n}\right) \\
& +\frac{1}{2} S\left[\alpha_{n} \gamma f\left(x_{n}\right)+\left(I-\alpha_{n} A\right) W_{n} u_{n}\right] \\
= & \frac{1-\alpha_{n}}{2}\left[\left(1-\lambda_{1}\right) I+\lambda_{1} T_{1} U_{n, 2}\right] u_{n}+\frac{\alpha_{n}}{2}\left(\gamma f\left(x_{n}\right)-A W_{n} u_{n}+W_{n} u_{n}\right) \\
& +\frac{1}{2} S\left[\alpha_{n} \gamma f\left(x_{n}\right)+\left(I-\alpha_{n} A\right) W_{n} u_{n}\right] \\
= & \frac{\left(1-\lambda_{1}\right)\left(1-\alpha_{n}\right)}{2} u_{n}+\frac{\lambda_{1}\left(1-\alpha_{n}\right)}{2} T_{1} U_{n, 2} u_{n}+\frac{\alpha_{n}}{2}\left(\gamma f\left(x_{n}\right)-A W_{n} u_{n}+W_{n} u_{n}\right) \\
& +\frac{1}{2} S\left[\alpha_{n} \gamma f\left(x_{n}\right)+\left(I-\alpha_{n} A\right) W_{n} u_{n}\right] .
\end{aligned}
$$


Note that

$$
0<\lim _{n \rightarrow \infty} \frac{\left(1-\lambda_{1}\right)\left(1-\alpha_{n}\right)}{2}=\frac{1-\lambda_{1}}{2}<1,
$$

and

$$
\frac{\lambda_{1}\left(1-\alpha_{n}\right)}{2}+\frac{1}{2}=\frac{1+\lambda_{1}}{2}-\frac{\lambda_{1}}{2} \alpha_{n} .
$$

From (3.3), we have

$$
\begin{aligned}
x_{n+1}= & {\left[1-\left(\frac{1+\lambda_{1}}{2}+\frac{1-\lambda_{1}}{2} \alpha_{n}\right)\right] u_{n}+\left(\frac{1+\lambda_{1}}{2}+\frac{1-\lambda_{1}}{2} \alpha_{n}\right) } \\
& \times\left(\frac{\lambda_{1}\left(1-\alpha_{n}\right)}{2} T_{1} U_{n, 2} u_{n}+\frac{\alpha_{n}}{2}\left(\gamma f\left(x_{n}\right)-A W_{n} u_{n}+W_{n} u_{n}\right)\right. \\
& \left.+\frac{1}{2} S\left[\alpha_{n} \gamma f\left(x_{n}\right)+\left(I-\alpha_{n} A\right) W_{n} u_{n}\right]\right) /\left(\frac{1+\lambda_{1}}{2}+\frac{1-\lambda_{1}}{2} \alpha_{n}\right) \\
= & {\left[1-\left(\frac{1+\lambda_{1}}{2}+\frac{1-\lambda_{1}}{2} \alpha_{n}\right)\right] u_{n}+\left(\frac{1+\lambda_{1}}{2}+\frac{1-\lambda_{1}}{2} \alpha_{n}\right) y_{n}, }
\end{aligned}
$$

where

$$
\begin{aligned}
y_{n}= & \left(\frac{\lambda_{1}\left(1-\alpha_{n}\right)}{2} T_{1} U_{n, 2} u_{n}+\frac{\alpha_{n}}{2}\left(\gamma f\left(x_{n}\right)-A W_{n} u_{n}+W_{n} u_{n}\right)\right. \\
& \left.+\frac{1}{2} S\left[\alpha_{n} \gamma f\left(x_{n}\right)+\left(I-\alpha_{n} A\right) W_{n} u_{n}\right]\right) /\left(\frac{1+\lambda_{1}}{2}+\frac{1-\lambda_{1}}{2} \alpha_{n}\right) \\
= & \left(\lambda_{1}\left(1-\alpha_{n}\right) T_{1} U_{n, 2} u_{n}+\alpha_{n}\left(\gamma f\left(x_{n}\right)-A W_{n} u_{n}+W_{n} u_{n}\right)\right. \\
& \left.+S\left[\alpha_{n} \gamma f\left(x_{n}\right)+\left(I-\alpha_{n} A\right) W_{n} u_{n}\right]\right) /\left(1+\lambda_{1}+\left(1-\lambda_{1}\right) \alpha_{n}\right) .
\end{aligned}
$$

Set $e_{n}=\gamma f\left(x_{n}\right)-A W_{n} u_{n}+W_{n} u_{n}$ and $d_{n}=\alpha_{n} \gamma f\left(x_{n}\right)+\left(I-\alpha_{n} A\right) W_{n} u_{n}$ for all $n$. Then

$$
y_{n}=\frac{\lambda_{1}\left(1-\alpha_{n}\right) T_{1} U_{n, 2} u_{n}+\alpha_{n} e_{n}+S d_{n}}{1+\lambda_{1}+\left(1-\lambda_{1}\right) \alpha_{n}}, \quad \forall n \geq 0 .
$$

It follows that

$$
\begin{aligned}
y_{n+1}-y_{n}= & \frac{\lambda_{1}\left(1-\alpha_{n+1}\right) T_{1} U_{n+1,2} u_{n+1}+\alpha_{n+1} e_{n+1}+S d_{n+1}}{1+\lambda_{1}+\left(1-\lambda_{1}\right) \alpha_{n+1}} \\
& -\frac{\lambda_{1}\left(1-\alpha_{n}\right) T_{1} U_{n, 2} u_{n}+\alpha_{n} e_{n}+S d_{n}}{1+\lambda_{1}+\left(1-\lambda_{1}\right) \alpha_{n}} \\
= & \frac{\lambda_{1}\left(1-\alpha_{n+1}\right)}{1+\lambda_{1}+\left(1-\lambda_{1}\right) \alpha_{n+1}}\left(T_{1} U_{n+1,2} u_{n+1}-T_{1} U_{n, 2} u_{n}\right) \\
& +\left(\frac{\lambda_{1}\left(1-\alpha_{n+1}\right)}{1+\lambda_{1}+\left(1-\lambda_{1}\right) \alpha_{n+1}}-\frac{\lambda_{1}\left(1-\alpha_{n}\right)}{1+\lambda_{1}+\left(1-\lambda_{1}\right) \alpha_{n}}\right) T_{1} U_{n, 2} u_{n} \\
& +\frac{\alpha_{n+1} e_{n+1}}{1+\lambda_{1}+\left(1-\lambda_{1}\right) \alpha_{n+1}}-\frac{\alpha_{n} e_{n}}{1+\lambda_{1}+\left(1-\lambda_{1}\right) \alpha_{n}} \\
& +\frac{S d_{n+1}-S d_{n}}{1+\lambda_{1}+\left(1-\lambda_{1}\right) \alpha_{n+1}}+\left(\frac{1}{1+\lambda_{1}+\left(1-\lambda_{1}\right) \alpha_{n+1}}-\frac{1}{1+\lambda_{1}+\left(1-\lambda_{1}\right) \alpha_{n}}\right) S d_{n} .
\end{aligned}
$$


Thus,

$$
\begin{aligned}
\left\|y_{n+1}-y_{n}\right\| \leq & \frac{\lambda_{1}\left(1-\alpha_{n+1}\right)}{1+\lambda_{1}+\left(1-\lambda_{1}\right) \alpha_{n+1}}\left\|T_{1} U_{n+1,2} u_{n+1}-T_{1} U_{n, 2} u_{n}\right\| \\
& +\left|\frac{\lambda_{1}\left(1-\alpha_{n+1}\right)}{1+\lambda_{1}+\left(1-\lambda_{1}\right) \alpha_{n+1}}-\frac{\lambda_{1}\left(1-\alpha_{n}\right)}{1+\lambda_{1}+\left(1-\lambda_{1}\right) \alpha_{n}}\right|\left\|T_{1} U_{n, 2} u_{n}\right\| \\
& +\frac{\alpha_{n+1}}{1+\lambda_{1}+\left(1-\lambda_{1}\right) \alpha_{n+1}}\left\|e_{n+1}\right\|+\frac{\alpha_{n}}{1+\lambda_{1}+\left(1-\lambda_{1}\right) \alpha_{n}}\left\|e_{n}\right\| \\
& +\frac{1}{1+\lambda_{1}+\left(1-\lambda_{1}\right) \alpha_{n+1}}\left\|S d_{n+1}-S d_{n}\right\| \\
& +\left|\frac{1}{1+\lambda_{1}+\left(1-\lambda_{1}\right) \alpha_{n+1}}-\frac{1}{1+\lambda_{1}+\left(1-\lambda_{1}\right) \alpha_{n}}\right|\left\|S d_{n}\right\| .
\end{aligned}
$$

Since $S$ is nonexpansive, we obtain that

$$
\begin{aligned}
\left\|S d_{n+1}-S d_{n}\right\| \leq & \left\|d_{n+1}-d_{n}\right\| \\
= & \left\|\alpha_{n+1} \gamma f\left(x_{n+1}\right)+\left(I-\alpha_{n+1} A\right) W_{n+1} u_{n+1}-\left(\alpha_{n} \gamma f\left(x_{n}\right)+\left(I-\alpha_{n} A\right) W_{n} u_{n}\right)\right\| \\
\leq & \left.\alpha_{n+1}\left\|\gamma f\left(x_{n+1}\right)-A W_{n+1} u_{n+1}\right\|+\alpha_{n} \| \gamma f\left(x_{n}\right)-A W_{n} u_{n}\right) \| \\
& \quad+\left\|W_{n+1} u_{n+1}-W_{n} u_{n}\right\| \\
\leq & \left.\alpha_{n+1}\left\|\gamma f\left(x_{n+1}\right)-A W_{n+1} u_{n+1}\right\|+\alpha_{n} \| \gamma f\left(x_{n}\right)-A W_{n} u_{n}\right) \| \\
& +\left\|W_{n+1} u_{n+1}-W_{n+1} u_{n}\right\|+\left\|W_{n+1} u_{n}-W_{n} u_{n}\right\| \\
\leq & \left.\alpha_{n+1}\left\|\gamma f\left(x_{n+1}\right)-A W_{n+1} u_{n+1}\right\|+\alpha_{n} \| \gamma f\left(x_{n}\right)-A W_{n} u_{n}\right)\|+\| u_{n+1}-u_{n} \| . \\
& +\left\|W_{n+1} u_{n}-W_{n} u_{n}\right\| .
\end{aligned}
$$

Since $T_{i}$ and $U_{n, i}$ are nonexpansive, we have

$$
\begin{aligned}
\left\|T_{1} U_{n+1,2} u_{n}-T_{1} U_{n, 2} u_{n}\right\| & \leq\left\|U_{n+1,2} u_{n}-U_{n, 2} u_{n}\right\| \\
& =\left\|\lambda_{2} T_{2} U_{n+1,3} u_{n}-\lambda_{2} T_{2} U_{n, 3} u_{n}\right\| \\
& \leq \lambda_{2}\left\|U_{n+1,3} u_{n}-U_{n, 3} u_{n}\right\| \\
& \leq \cdots \\
& \leq \lambda_{2} \cdots \lambda_{n}\left\|U_{n+1, n+1} u_{n}-U_{n, n+1} u_{n}\right\| \\
& \leq M \prod_{i=2}^{n} \lambda_{i}
\end{aligned}
$$

where $M>0$ is a constant such that $\left\|U_{n+1, n+1} u_{n}-U_{n, n+1} u_{n}\right\| \leq M$ for all $n \geq 0$. So,

$$
\begin{aligned}
\left\|T_{1} U_{n+1,2} u_{n+1}-T_{1} U_{n, 2} u_{n}\right\| & \leq\left\|T_{1} U_{n+1,2} u_{n+1}-T_{1} U_{n+1,2} u_{n}\right\|+\left\|T_{1} U_{n+1,2} u_{n}-T_{1} U_{n, 2} u_{n}\right\| \\
& \leq\left\|u_{n+1}-u_{n}\right\|+M \prod_{i=2}^{n} \lambda_{i}
\end{aligned}
$$


Hence,

$$
\begin{aligned}
\left\|y_{n+1}-y_{n}\right\| \leq & \frac{\lambda_{1}\left(1-\alpha_{n+1}\right)}{1+\lambda_{1}+\left(1-\lambda_{1}\right) \alpha_{n+1}}\left\|u_{n+1}-u_{n}\right\|+M \prod_{i=2}^{n} \lambda_{i} \\
& +\left|\frac{\lambda_{1}\left(1-\alpha_{n+1}\right)}{1+\lambda_{1}+\left(1-\lambda_{1}\right) \alpha_{n+1}}-\frac{\lambda_{1}\left(1-\alpha_{n}\right)}{1+\lambda_{1}+\left(1-\lambda_{1}\right) \alpha_{n}}\right|\left\|T_{1} U_{n, 2} u_{n}\right\| \\
& +\frac{\alpha_{n+1}}{1+\lambda_{1}+\left(1-\lambda_{1}\right) \alpha_{n+1}}\left\|e_{n+1}\right\|+\frac{\alpha_{n}}{1+\lambda_{1}+\left(1-\lambda_{1}\right) \alpha_{n}}\left\|e_{n}\right\| \\
& +\frac{1}{1+\lambda_{1}+\left(1-\lambda_{1}\right) \alpha_{n+1}}\left(\alpha_{n+1}\left\|\gamma f\left(x_{n+1}\right)-A W_{n+1} u_{n+1}\right\|\right. \\
& \left.+\alpha_{n}\left\|\gamma f\left(x_{n}\right)-A W_{n} u_{n}\right\|+\left\|u_{n+1}-u_{n}\right\|\right)+\left\|W_{n+1} u_{n}-W_{n} u_{n}\right\| \\
& +\left|\frac{1}{1+\lambda_{1}+\left(1-\lambda_{1}\right) \alpha_{n+1}}-\frac{1}{1+\lambda_{1}+\left(1-\lambda_{1}\right) \alpha_{n}}\right|\left\|S d_{n}\right\| \\
= & \frac{\lambda_{1}\left(1-\alpha_{n+1}\right)}{1+\lambda_{1}+\left(1-\lambda_{1}\right) \alpha_{n+1}}\left\|u_{n+1}-u_{n}\right\| \\
& +\left|\frac{\lambda_{1}\left(1-\alpha_{n+1}\right)}{1+\lambda_{1}+\left(1-\lambda_{1}\right) \alpha_{n+1}}-\frac{\lambda_{1}\left(1-\alpha_{n}\right)}{1+\lambda_{1}+\left(1-\lambda_{1}\right) \alpha_{n}}\right|\left\|T_{1} U_{n, 2} u_{n}\right\| \\
& +\frac{\alpha_{n+1}}{1+\lambda_{1}+\left(1-\lambda_{1}\right) \alpha_{n+1}}\left\|e_{n+1}\right\|+\frac{\alpha_{n}}{1+\lambda_{1}+\left(1-\lambda_{1}\right) \alpha_{n}}\left\|e_{n}\right\| \\
& +\frac{1}{1+\lambda_{1}+\left(1-\lambda_{1}\right) \alpha_{n+1}}\left(\alpha_{n+1}\left\|\gamma f\left(x_{n+1}\right)-A W_{n+1} u_{n+1}\right\|\right. \\
& \left.+\alpha_{n}\left\|\gamma f\left(x_{n}\right)-A W_{n} u_{n}\right\|+\left\|u_{n+1}-u_{n}\right\|\right)+\left\|W_{n+1} u_{n}-W_{n} u_{n}\right\| \\
& +\mid \frac{1}{1+\lambda_{1}+\left(1-\lambda_{1}\right) \alpha_{n+1} \| .} . \\
& \\
& \left.+1-\lambda_{1}\right) \alpha_{n} \mid
\end{aligned}
$$

Note that:

(1) By condition (C1), we have

$$
\frac{\lambda_{1}\left(1-\alpha_{n+1}\right)}{1+\lambda_{1}+\left(1-\lambda_{1}\right) \alpha_{n+1}}-\frac{\lambda_{1}\left(1-\alpha_{n}\right)}{1+\lambda_{1}+\left(1-\lambda_{1}\right) \alpha_{n}} \rightarrow 0
$$

and

$$
\frac{1}{1+\lambda_{1}+\left(1-\lambda_{1}\right) \alpha_{n+1}}-\frac{1}{1+\lambda_{1}+\left(1-\lambda_{1}\right) \alpha_{n}} \rightarrow 0 \text {. }
$$

(2) $\left\|W_{n+1} u_{n}-W_{n} u_{n}\right\| \rightarrow 0$ as $n \rightarrow \infty$ because of Step 2 .

Therefore,

$$
\limsup _{n \rightarrow \infty}\left(\left\|y_{n+1}-y_{n}\right\|-\left\|u_{n+1}-u_{n}\right\|\right) \leq 0
$$

By Lemma 2.2, we get

$$
\lim _{n \rightarrow \infty}\left\|y_{n}-u_{n}\right\|=0 \text {. }
$$


Hence, from (3.4), we deduce

$$
\lim _{n \rightarrow \infty}\left\|x_{n+1}-x_{n}\right\|=\lim _{n \rightarrow \infty}\left(\frac{1+\lambda_{1}}{2}+\frac{1-\lambda_{1}}{2} \alpha_{n}\right)\left\|y_{n}-u_{n}\right\|=0 .
$$

Step 4. Show that $\left\|x_{n}-W_{n} u_{n}\right\| \rightarrow 0$ as $n \rightarrow \infty$. Indeed, we have

$$
\begin{aligned}
\left\|x_{n}-W_{n} u_{n}\right\| & \leq\left\|x_{n}-x_{n+1}\right\|+\left\|x_{n+1}-W_{n} u_{n}\right\| \\
& =\left\|x_{n}-x_{n+1}\right\|+\left\|P_{C}\left[\alpha_{n} \gamma f\left(x_{n}\right)+\left(I-\alpha_{n} A\right) W_{n} u_{n}\right]-W_{n} u_{n}\right\| \\
& \leq\left\|x_{n}-x_{n+1}\right\|+\left\|\alpha_{n} \gamma f\left(x_{n}\right)+\left(I-\alpha_{n} A\right) W_{n} u_{n}-W_{n} u_{n}\right\| \\
& =\left\|x_{n}-x_{n+1}\right\|+\left\|-\alpha_{n} A W_{n} u_{n}+\alpha_{n} \gamma f\left(x_{n}\right)\right\| \\
& \leq\left\|x_{n}-x_{n+1}\right\|+\alpha_{n}\left(\|A\|\left\|W_{n} u_{n}\right\|+\gamma\left\|f\left(x_{n}\right)\right\|\right) .
\end{aligned}
$$

Then

$$
\lim _{n \rightarrow \infty}\left\|x_{n}-W_{n} u_{n}\right\| \leq \lim _{n \rightarrow \infty}\left\|x_{n}-x_{n+1}\right\|+\alpha_{n}\left(\|A\|\left\|W_{n} u_{n}\right\|+\gamma\left\|f\left(x_{n}\right)\right\|\right)=0
$$

Thus, from (3.6), we obtain

$$
\lim _{n \rightarrow \infty}\left\|x_{n}-W_{n} u_{n}\right\|=0
$$

Step 5. Show that $\left\|x_{n}-u_{n}\right\| \rightarrow 0$ as $n \rightarrow \infty$.

Let $\hat{x} \in \Omega$. Since $T_{r_{n}}$ is firmly nonexpansive, it follows

$$
\begin{aligned}
\left\|\hat{x}-u_{n}\right\|^{2} & =\left\|T_{r_{n}} \hat{x}-T_{r_{n}} x_{n}\right\|^{2} \\
& \leq\left\langle T_{r_{n}} x_{n}-T_{r_{n}} \hat{x}, x_{n}-\hat{x}\right\rangle \\
& \leq\left\langle T_{r_{n}} x_{n}-\hat{x}, x_{n}-\hat{x}\right\rangle \\
& =\left\langle u_{n}-\hat{x}, x_{n}-\hat{x}\right\rangle \\
& =\frac{1}{2}\left(\left\|u_{n}-\hat{x}\right\|^{2}+\left\|x_{n}-\hat{x}\right\|^{2}-\left\|x_{n}-u_{n}\right\|^{2}\right) .
\end{aligned}
$$

Then

$$
\left\|u_{n}-\hat{x}\right\|^{2} \leq\left\|x_{n}-\hat{x}\right\|^{2}-\left\|x_{n}-u_{n}\right\|^{2} \text {. }
$$

Since we have

$$
\begin{aligned}
\left\|x_{n+1}-\hat{x}\right\|^{2} & =\left\|P_{C}\left[\alpha_{n} \gamma f\left(x_{n}\right)+\left(I-\alpha_{n} A\right) W_{n} u_{n}\right]-P_{C} \hat{x}\right\|^{2} \\
& =\left\|\alpha_{n} \gamma f\left(x_{n}\right)+\left(I-\alpha_{n} A\right) W_{n} u_{n}-\hat{x}\right\|^{2} \\
& =\left\|\left(I-\alpha_{n} A\right)\left(W_{n} u_{n}-\hat{x}\right)+\alpha_{n}\left(\gamma f\left(x_{n}\right)-A \hat{x}\right)\right\|^{2} \\
& \leq\left(1-\alpha_{n} \bar{\gamma}\right)^{2}\left\|W_{n} u_{n}-\hat{x}\right\|^{2}+2 \alpha_{n}\left\langle\gamma f\left(x_{n}\right)-A \hat{x}, x_{n+1}-\hat{x}\right\rangle \\
& \leq\left(1-\alpha_{n} \bar{\gamma}\right)^{2}\left\|u_{n}-\hat{x}\right\|^{2}+2 \alpha_{n} \gamma\left\langle f\left(x_{n}\right)-f(\hat{x}), x_{n+1}-\hat{x}\right\rangle
\end{aligned}
$$




$$
\begin{aligned}
& +2 \alpha_{n}\left\langle\gamma f(\hat{x})-A \hat{x}, x_{n+1}-\hat{x}\right\rangle \\
\leq & \left(1-\alpha_{n} \bar{\gamma}\right)^{2}\left(\left\|x_{n}-\hat{x}\right\|^{2}-\left\|x_{n}-u_{n}\right\|^{2}\right)+2 \alpha_{n} \gamma \alpha\left\|x_{n}-\hat{x}\right\|\left\|x_{n+1}-\hat{x}\right\| \\
& +2 \alpha_{n}\|\gamma f(\hat{x})-A \hat{x}\|\left\|x_{n+1}-\hat{x}\right\| \\
= & \left(1-2 \alpha_{n} \bar{\gamma}+\left(\alpha_{n} \bar{\gamma}\right)^{2}\right)\left\|x_{n}-\hat{x}\right\|^{2}-\left(1-\alpha_{n} \bar{\gamma}\right)^{2}\left\|x_{n}-u_{n}\right\|^{2} \\
& +2 \alpha_{n} \gamma \alpha\left\|x_{n}-\hat{x}\right\|\left\|x_{n+1}-\hat{x}\right\|+2 \alpha_{n}\|\gamma f(\hat{x})-A \hat{x}\|\left\|x_{n+1}-\hat{x}\right\| \\
\leq & \left\|x_{n}-\hat{x}\right\|^{2}+\alpha_{n} \bar{\gamma}^{2}\left\|x_{n}-\hat{x}\right\|^{2}-\left(1-\alpha_{n} \bar{\gamma}\right)^{2}\left\|x_{n}-u_{n}\right\|^{2} \\
& +2 \alpha_{n} \gamma \alpha\left\|x_{n}-\hat{x}\right\|\left\|x_{n+1}-\hat{x}\right\|+2 \alpha_{n}\|\gamma f(\hat{x})-A \hat{x}\|\left\|x_{n+1}-\hat{x}\right\|,
\end{aligned}
$$

and hence

$$
\begin{aligned}
\left(1-\alpha_{n} \bar{\gamma}\right)^{2}\left\|x_{n}-u_{n}\right\|^{2} \leq & \left\|x_{n}-\hat{x}\right\|^{2}-\left\|x_{n+1}-\hat{x}\right\|^{2}+\alpha_{n} \bar{\gamma}^{2}\left\|x_{n}-\hat{x}\right\|^{2} \\
& +2 \alpha_{n} \gamma \alpha\left\|x_{n}-\hat{x}\right\|\left\|x_{n+1}-\hat{x}\right\|+2 \alpha_{n}\|\gamma f(\hat{x})-A \hat{x}\|\left\|x_{n+1}-\hat{x}\right\| \\
\leq & \left\|x_{n}-x_{n+1}\right\|\left(\left\|x_{n}-\hat{x}\right\|\left\|x_{n+1}-\hat{x}\right\|\right)+\alpha_{n} \bar{\gamma}^{2}\left\|x_{n}-\hat{x}\right\|^{2} \\
& +2 \alpha_{n} \gamma \alpha\left\|x_{n}-\hat{x}\right\|\left\|x_{n+1}-\hat{x}\right\|+2 \alpha_{n}\|\gamma f(\hat{x})-A \hat{x}\|\left\|x_{n+1}-\hat{x}\right\| .
\end{aligned}
$$

Therefore, we have $\left\|x_{n}-u_{n}\right\| \rightarrow 0$ as $n \rightarrow \infty$.

Step 6. Show that $\lim _{\sup } \operatorname{su}_{n \rightarrow \infty}\left\langle\gamma f\left(x^{*}\right)-A x^{*}, x_{n}-x^{*}\right\rangle \leq 0$.

We can choose a subsequence $\left\{x_{n_{i}}\right\}$ of $\left\{x_{n}\right\}$ such that

$$
\lim _{i \rightarrow \infty}\left\langle\gamma f\left(x^{*}\right)-A x^{*}, x_{n_{i}}-x^{*}\right\rangle=\limsup _{n \rightarrow \infty}\left\langle\gamma f\left(x^{*}\right)-A x^{*}, x_{n}-x^{*}\right\rangle .
$$

Let

$$
A\left(x_{n_{i}}\right)=\left\{x \in H: \limsup _{i \rightarrow \infty}\left\|x_{n_{i}}-x\right\|=\inf _{y \in H} \limsup _{i \rightarrow \infty}\left\|x_{n_{i}}-y\right\|\right\}
$$

be the asymptotic center of $\left\{x_{n_{i}}\right\}$. Since $\left\{x_{n_{i}}\right\}$ is bounded and $H$ is a Hilbert space, it is well known that $A\left(x_{n_{i}}\right)$ is a singleton; say $A\left(x_{n_{i}}\right)=\{\tilde{x}\}$. Set

$$
L=\sup _{i \in \mathbb{N}}\left\|\gamma f\left(x_{n_{i}}\right)-A W_{n_{i}} u_{n_{i}}\right\|
$$

and for every $x \in H$ define

$$
W x=\lim _{i \rightarrow \infty} W_{n_{i}} x
$$

and

$$
T_{r}(x)=\left\{z \in H: F(z, y)+\frac{1}{r}\langle y-z, z-x\rangle \geq 0, \forall y \in H\right\} .
$$

Note that

$$
\begin{aligned}
\left\|x_{n_{i}}-W \tilde{x}\right\| & \leq\left\|x_{n_{i}+1}-x_{n_{i}}\right\|+\left\|x_{n_{i}+1}-W \tilde{x}\right\| \\
& =\left\|x_{n_{i}+1}-x_{n_{i}}\right\|+\left\|P_{C}\left[\alpha_{n_{i}} \gamma f\left(x_{n_{i}}\right)+\left(I-\alpha_{n_{i}} A\right) W_{n_{i}} u_{n_{i}}\right]-W \tilde{x}\right\|
\end{aligned}
$$




$$
\begin{aligned}
\leq & \left\|x_{n_{i}+1}-x_{n_{i}}\right\|+\left\|\alpha_{n_{i}} \gamma f\left(x_{n_{i}}\right)+\left(I-\alpha_{n_{i}} A\right) W_{n_{i}} u_{n_{i}}-W \tilde{x}\right\| \\
= & \left\|x_{n_{i}+1}-x_{n_{i}}\right\|+\left\|W_{n_{i}} u_{n_{i}}-W \tilde{x}+\alpha_{n_{i}}\left(\gamma f\left(x_{n_{i}}\right)-A W_{n_{i}} u_{n_{i}}\right)\right\| \\
\leq & \left\|x_{n_{i}+1}-x_{n_{i}}\right\|+\left\|W_{n_{i}} u_{n_{i}}-W_{n_{i}} x_{n_{i}}\right\|+\left\|W_{n_{i}} x_{n_{i}}-W_{n_{i}} \tilde{x}\right\| \\
& \quad+\left\|W_{n_{i}} \tilde{x}-W \tilde{x}\right\|+\alpha_{n_{i}} L \\
\leq & \left\|x_{n_{i}+1}-x_{n_{i}}\right\|+\left\|u_{n_{i}}-x_{n_{i}}\right\|+\left\|x_{n_{i}}-\tilde{x}\right\|+\left\|W_{n_{i}} \tilde{x}-W \tilde{x}\right\|+\alpha_{n_{i}} L .
\end{aligned}
$$

By Steps 1-5, condition (C1) and (3.7), we derive

$$
\begin{aligned}
\limsup _{i \rightarrow \infty}\left\|x_{n_{i}}-W \tilde{x}\right\| & \leq \limsup _{i \rightarrow \infty}\left\|u_{n_{i}}-x_{n_{i}}\right\|+\left\|x_{n_{i}}-\tilde{x}\right\|+\left\|W_{n_{i}} \tilde{x}-W \tilde{x}\right\| \\
& \leq \limsup _{i \rightarrow \infty}\left\|x_{n_{i}}-\tilde{x}\right\| .
\end{aligned}
$$

That is, $W \tilde{x} \in A\left(x_{n_{i}}\right)$. Therefore $W \tilde{x}=\tilde{x}$. Next, we show that $\tilde{x}=T_{r} \tilde{x}$.

Note that for any $x \in H$ and $a, b>0$, we have

$$
F\left(T_{a} x, y\right)+\frac{1}{a}\left\langle y-T_{a} x, T_{a} x-x\right\rangle \geq 0, \quad \forall y \in H
$$

and

$$
F\left(T_{b} x, y\right)+\frac{1}{b}\left\langle y-T_{b} x, T_{b} x-x\right\rangle \geq 0, \quad \forall y \in H
$$

then

$$
F\left(T_{a} x, T_{b} x\right)+\frac{1}{a}\left\langle T_{b} x-T_{a} x, T_{a} x-x\right\rangle \geq 0
$$

and

$$
F\left(T_{b} x, T_{a} x\right)+\frac{1}{b}\left\langle T_{a} x-T_{b} x, T_{a} x-x\right\rangle \geq 0 .
$$

Summing up the last inequalities and using (A2), we obtain

$$
\left\langle T_{a} x-T_{b} x, \frac{T_{b} x-x}{b}-\frac{T_{a} x-x}{a}\right\rangle \geq 0 .
$$

Hence we have

$$
\begin{aligned}
0 & \leq\left\langle T_{a} x-T_{b} x, T_{b} x-x-\frac{b}{a}\left(T_{a} x-x\right)\right\rangle \\
& =\left\langle T_{a} x-T_{b} x, T_{b} x-T_{a} x+T_{a} x-x-\frac{b}{a}\left(T_{a} x-x\right)\right\rangle \\
& =\left\langle T_{a} x-T_{b} x,\left(T_{b} x-T_{a} x\right)+\left(1-\frac{b}{a}\right)\left(T_{a} x-x\right)\right\rangle \\
& \leq-\left\|T_{a} x-T_{b} x\right\|^{2}+\left|1-\frac{b}{a}\right|\left\|T_{a} x-T_{b} x\right\|\left(\left\|T_{a} x\right\|+\|x\|\right) .
\end{aligned}
$$


We derive then

$$
\left\|T_{a} x-T_{b} x\right\| \leq \frac{|b-a|}{a}\left(\left\|T_{a} x\right\|+\|x\|\right) .
$$

It follows that

$$
\begin{aligned}
\left\|x_{n_{i}}-T_{r} \tilde{x}\right\| \leq & \left\|x_{n_{i}+1}-x_{n_{i}}\right\|+\left\|x_{n_{i}+1}-T_{r} \tilde{x}\right\| \\
= & \left\|x_{n_{i}+1}-x_{n_{i}}\right\|+\left\|P_{C}\left[\alpha_{n_{i}} \gamma f\left(x_{n_{i}}\right)+\left(I-\alpha_{n_{i}} A\right) W_{n_{i}} u_{n_{i}}\right]-T_{r} \tilde{x}\right\| \\
\leq & \left\|x_{n_{i}+1}-x_{n_{i}}\right\|+\left\|\alpha_{n_{i}} \gamma f\left(x_{n_{i}}\right)+\left(I-\alpha_{n_{i}} A\right) W_{n_{i}} u_{n_{i}}-T_{r} \tilde{x}\right\| \\
= & \left\|x_{n_{i}+1}-x_{n_{i}}\right\|+\left\|W_{n_{i}} u_{n_{i}}-T_{r} \tilde{x}+\alpha_{n_{i}}\left(\gamma f\left(x_{n_{i}}\right)-A W_{n_{i}} u_{n_{i}}\right)\right\| \\
\leq & \left\|x_{n_{i}+1}-x_{n_{i}}\right\|+\left\|W_{n_{i}} u_{n_{i}}-x_{n_{i}}\right\|+\left\|T_{r_{n_{i}}} x_{n_{i}}-T_{r_{n_{i}}} \tilde{x}\right\|+\left\|x_{n_{i}}-T_{r_{n_{i}}} x_{n_{i}}\right\| \\
& \quad+\left\|T_{r_{n_{i}}} \tilde{x}-T_{r} \tilde{x}\right\|+\alpha_{n_{i}} L \\
\leq & \left\|x_{n_{i}+1}-x_{n_{i}}\right\|+\left\|u_{n_{i}}-x_{n_{i}}\right\|+\left\|x_{n_{i}}-\tilde{x}\right\|+\left\|x_{n_{i}}-u_{n_{i}}\right\| \\
& \quad+\left\|T_{r_{n_{i}}} \tilde{x}-T_{r} \tilde{x}\right\|+\alpha_{n_{i}} L \\
\leq & \left\|x_{n_{i}+1}-x_{n_{i}}\right\|+\left\|u_{n_{i}}-x_{n_{i}}\right\|+\left\|x_{n_{i}}-\tilde{x}\right\|+\left\|x_{n_{i}}-u_{n_{i}}\right\| \\
& \quad+\frac{\left|r_{n_{i}}-r\right|}{r}\left(\left\|T_{r} \tilde{x}\right\|+\|\tilde{x}\|\right)+\alpha_{n_{i}} L .
\end{aligned}
$$

By Steps 2-5, conditions (C1) and (C3), we obtain

$$
\limsup _{i \rightarrow \infty}\left\|x_{n_{i}}-T_{r} \tilde{x}\right\| \leq \limsup _{i \rightarrow \infty}\left\|x_{n_{i}}-\tilde{x}\right\|
$$

and $\tilde{x}=T_{r} \tilde{x}$. Thus $\tilde{x} \in F(W) \cap F\left(T_{r}\right)=\Omega$ by Lemma 2.3 and 2.9. Fix $t \in(0,1), x \in H$ and set $y=\tilde{x}+t x$. Then

$$
\left\|x_{n_{i}}-\tilde{x}-t x\right\|^{2} \leq\left\|x_{n_{i}}-\tilde{x}\right\|^{2}+2 t\left\langle x, \tilde{x}+t x-x_{n_{i}}\right\rangle .
$$

By the minimizing property of $\tilde{x}$ and since $\|\cdot\|^{2}$ is continuous and increasing in $[0, \infty)$, we have

$$
\begin{aligned}
\limsup _{i \rightarrow \infty}\left\|x_{n_{i}}-\tilde{x}\right\|^{2} & \leq \limsup _{i \rightarrow \infty}\left\|x_{n_{i}}-\tilde{x}-t x\right\|^{2} \\
& \leq \limsup _{i \rightarrow \infty}\left\|x_{n_{i}}-\tilde{x}\right\|^{2}+2 t \limsup _{i \rightarrow \infty}\left\langle x, \tilde{x}+t x-x_{n_{i}}\right\rangle .
\end{aligned}
$$

Thus,

$$
\limsup _{i \rightarrow \infty}\left\langle x, \tilde{x}+t x-x_{n_{i}}\right\rangle \geq 0
$$

On the other hand,

$$
\left\langle x, \tilde{x}-x_{n_{i}}\right\rangle=\left\langle x, \tilde{x}+t x-x_{n_{i}}\right\rangle-t\|x\|^{2} .
$$


Hence we obtain

$$
\limsup _{i \rightarrow \infty}\left\langle x, \tilde{x}-x_{n_{i}}\right\rangle=\lim _{t \rightarrow 0}\left(\limsup _{i \rightarrow \infty}\left\langle x, \tilde{x}+t x-x_{n_{i}}\right\rangle-t\|x\|^{2}\right) \geq 0 .
$$

Set $x=\gamma f\left(x^{*}\right)-A x^{*}$. Since $\tilde{x} \in \Omega$, we obtain

$$
\begin{aligned}
0 & \leq \limsup _{i \rightarrow \infty}\left\langle\gamma f\left(x^{*}\right)-A x^{*}, \tilde{x}-x_{n_{i}}\right\rangle \\
& \leq\left\langle\gamma f\left(x^{*}\right)-A x^{*}, \tilde{x}-x^{*}\right\rangle+\lim _{i \rightarrow \infty}\left\langle\gamma f\left(x^{*}\right)-A x^{*}, x^{*}-x_{n_{i}}\right\rangle \\
& \leq \lim _{i \rightarrow \infty}\left\langle\gamma f\left(x^{*}\right)-A x^{*}, x^{*}-x_{n_{i}}\right\rangle .
\end{aligned}
$$

So that

$$
\limsup _{n \rightarrow \infty}\left\langle\gamma f\left(x^{*}\right)-A x^{*}, x_{n}-x^{*}\right\rangle=-\lim _{i \rightarrow \infty}\left\langle\gamma f\left(x^{*}\right)-A x^{*}, x_{n_{i}}-x^{*}\right\rangle \leq 0 .
$$

Step 7. Show that both $\left\{x_{n}\right\}$ and $\left\{u_{n}\right\}$ strongly converge to $x^{*} \in \Omega$, which is the unique solution of the variational inequality (3.2). Indeed, we note that

$$
\left\|x_{n+1}-x^{*}\right\|^{2}=\left\langle x_{n+1}-d_{n}, x_{n+1}-x^{*}\right\rangle+\left\langle d_{n}-x^{*}, x_{n+1}-x^{*}\right\rangle .
$$

Since $\left\langle x_{n+1}-d_{n}, x_{n+1}-x^{*}\right\rangle \leq 0$, we get

$$
\begin{aligned}
\left\|x_{n+1}-x^{*}\right\|^{2} \leq & \left\langle d_{n}-x^{*}, x_{n+1}-x^{*}\right\rangle \\
= & \left\langle\alpha_{n} \gamma f\left(x_{n}\right)+\left(I-\alpha_{n} A\right) W_{n} u_{n}-x^{*}, x_{n+1}-x^{*}\right\rangle \\
= & \left\langle\alpha_{n} \gamma f\left(x_{n}\right)-\alpha_{n} \gamma f\left(x^{*}\right)+W_{n} u_{n}-\alpha_{n} A W_{n} u_{n}-x^{*}\right. \\
& \left.+\alpha_{n} A x^{*}+\alpha_{n} \gamma f\left(x^{*}\right)-\alpha_{n} A x^{*}, x_{n+1}-x^{*}\right\rangle \\
= & \left\langle\alpha_{n} \gamma\left(f\left(x_{n}\right)-f\left(x^{*}\right)\right)+\left(I-\alpha_{n} A\right)\left(W_{n} u_{n}-x^{*}\right), x_{n+1}-x^{*}\right\rangle \\
& +\alpha_{n}\left\langle\gamma f\left(x^{*}\right)-A x^{*}, x_{n+1}-x^{*}\right\rangle \\
\leq & \left(\alpha_{n} \gamma\left\|f\left(x_{n}\right)-f\left(x^{*}\right)\right\|+\left\|I-\alpha_{n} A\right\|\left\|W_{n} u_{n}-x^{*}\right\|\right)\left\|x_{n+1}-x^{*}\right\| \\
& +\alpha_{n}\left\langle\gamma f\left(x^{*}\right)-A x^{*}, x_{n+1}-x^{*}\right\rangle \\
\leq & \left(1-\alpha_{n}(\bar{\gamma}-\gamma \alpha)\right)\left\|x_{n}-x^{*}\right\|\left\|x_{n+1}-x^{*}\right\|+\alpha_{n}\left\langle\gamma f\left(x^{*}\right)-A x^{*}, x_{n+1}-x^{*}\right\rangle \\
\leq & \left(\frac{\left[1-\alpha_{n}(\bar{\gamma}-\gamma \alpha)\right]^{2}}{2}\right)\left\|x_{n}-x^{*}\right\|^{2}+\frac{1}{2}\left\|x_{n+1}-x^{*}\right\|^{2} \\
& +\alpha_{n}\left\langle\gamma f\left(x^{*}\right)-A x^{*}, x_{n+1}-x^{*}\right\rangle .
\end{aligned}
$$

It then follows that

$$
\left\|x_{n+1}-x^{*}\right\|^{2} \leq\left[1-\alpha_{n}(\bar{\gamma}-\gamma \alpha)\right]\left\|x_{n}-x^{*}\right\|^{2}+2 \alpha_{n}\left\langle\gamma f\left(x^{*}\right)-A x^{*}, x_{n+1}-x^{*}\right\rangle .
$$

Let $a_{n}=\left\|x_{n}-x^{*}\right\|^{2}, \gamma_{n}=\alpha_{n}(\bar{\gamma}-\gamma \alpha)$ and $\delta_{n}=2 \alpha_{n}\left\langle\gamma f\left(x^{*}\right)-A x^{*}, x_{n+1}-x^{*}\right\rangle$. 
Then, we can write the last inequality as

$$
a_{n+1} \leq\left(1-\gamma_{n}\right) a_{n}+\delta_{n}
$$

Note that in virtue of condition (C2), $\sum_{n=1}^{\infty} \gamma_{n}=\infty$. Moreover,

$$
\limsup _{n \rightarrow \infty} \frac{\delta_{n}}{\gamma_{n}}=\frac{1}{\bar{\gamma}-\gamma \alpha} \limsup _{n \rightarrow \infty} 2\left\langle\gamma f\left(x^{*}\right)-A x^{*}, x_{n+1}-x^{*}\right\rangle .
$$

By Step 5, we obtain

$$
\limsup _{n \rightarrow \infty} \frac{\delta_{n}}{\gamma_{n}} \leq 0
$$

Now, applying Lemma 2.6 to (3.8), we conclude that $x_{n} \rightarrow x^{*}$ as $n \rightarrow \infty$. Furthermore, since $\left\|u_{n}-x^{*}\right\|=\left\|T_{r_{n}} x_{n}-T_{r_{n}} x^{*}\right\| \leq\left\|x_{n}-x^{*}\right\|$, we then have that $u_{n} \rightarrow x^{*}$ as $n \rightarrow \infty$. The proof is now complete.

Setting $A \equiv I$ and $\gamma=1$ in Theorem 3.1, we have the following result.

Corollary 3.2 Let $C$ be a nonempty closed convex subset of a real Hilbert space H. Let $F: C \times C \rightarrow \mathbb{R}$ be an equilibrium bifunction satisfying the conditions:

(1) $F$ is monotone, that is, $F(x, y)+F(y, x) \leq 0$ for all $x, y \in C$;

(2) for each $x, y, z \in C, \lim _{t \rightarrow 0} F(t z+(1-t) x, y) \leq F(x, y)$;

(3) for each $x \in C, y \mapsto F(x, y)$ is convex and lower semicontinuous.

Let $\left\{T_{i}\right\}_{i=1}^{\infty}$ be an infinite family of nonexpansive mappings of $C$ into $C$ such that $\bigcap_{i=1}^{\infty} F\left(T_{i}\right) \cap E P(F) \neq \emptyset$. Suppose $\left\{\alpha_{n}\right\} \subset(0,1)$ and $\left\{r_{n}\right\} \subset(0, \infty)$ satisfy the following conditions:

(1) $\lim _{n \rightarrow \infty} \alpha_{n}=0$ and $\sum_{n=1}^{\infty} \alpha_{n}=\infty$;

(2) $\liminf _{n \rightarrow \infty} r_{n}>0$ and $\lim _{n \rightarrow \infty}\left(r_{n+1}-r_{n}\right)=0$.

Let fbe a contraction of $C$ into itself, and let $x_{0} \in H$ be given arbitrarily. Then the sequences $\left\{x_{n}\right\}$ and $\left\{y_{n}\right\}$ generated iteratively by

$$
\left\{\begin{array}{l}
F\left(y_{n}, x\right)+\frac{1}{r_{n}}\left\langle x-y_{n}, y_{n}-x_{n}\right\rangle \geq 0, \quad \forall x \in C, \\
x_{n+1}=\alpha_{n} f\left(x_{n}\right)+\left(1-\alpha_{n}\right) W_{n} y_{n}
\end{array}\right.
$$

converge strongly to $x^{*} \in \bigcap_{i=1}^{\infty} F\left(T_{i}\right) \cap E P(F)$, the unique solution of the minimization problem

$$
\min _{x \in \bigcap_{i=1}^{\infty} F\left(T_{i}\right) \cap E P(F)} \frac{1}{2}\|x\|^{2}-h(x),
$$

where $h$ is a potential function for $f$.

Setting $F=0$ in Theorem 3.1, we have the following result.

Corollary 3.3 ([11]) Let $C$ be a nonempty closed convex subset of a real Hilbert space $H$. Let $\left\{T_{n}\right\}_{n=1}^{\infty}$ be a sequence of nonexpansive mappings from $C$ to $C$ such that the common 
fixed point set $\Omega=\bigcap_{n=1}^{\infty} F\left(T_{n}\right) \neq \emptyset$. Let $f: C \rightarrow H$ be an $\alpha$-contraction and $A: H \rightarrow H$ be a strongly positive bounded linear operator with a coefficient $\bar{\gamma}>0$. Let $\gamma$ be a constant such that $0<\gamma \alpha<\bar{\gamma}$. For an arbitrary initial point $x_{0}$ belonging to $C$, one defines a sequence $\left\{x_{n}\right\}_{n \geq 0}$ iteratively

$$
x_{n+1}=P_{C}\left[\alpha_{n} \gamma f\left(x_{n}\right)+\left(I-\alpha_{n} A\right) W_{n} x_{n}\right], \quad \forall n \geq 0,
$$

where $\left\{\alpha_{n}\right\}$ is a real sequence in $[0,1]$. Assume that the sequence $\left\{\alpha_{n}\right\}$ satisfies the following conditions:

(C1) $\lim _{n \rightarrow \infty} \alpha_{n}=0$;

(C2) $\sum_{n=1}^{\infty} \alpha_{n}=\infty$.

Then the sequence $\left\{x_{n}\right\}$ generated by (3.10) converges in norm to the unique solution $x^{*}$, which solves the following variational inequality:

$$
x^{*} \in \Omega \quad \text { such that }\left\langle(A-\gamma f) x^{*}, x^{*}-\hat{x}\right\rangle \leq 0, \forall \hat{x} \in \Omega \text {. }
$$

\section{Competing interests}

The author declares that they have no competing interests.

\section{Acknowledgements}

The author would like to thank Asst. Prof. Dr. Rabian Wangkeeree for his useful suggestions and the referees for their valuable comments and suggestions.

\section{Received: 2 October 2012 Accepted: 7 March 2013 Published: 3 April 2013}

\section{References}

1. Qin, X, Shang, M, Su, Y: Strong convergence of a general iterative algorithm for equilibrium problems and variational inequalities problems. Math. Comput. Model. 48, 1033-1046 (2008)

2. Takahashi, S, Takahashi, W: Viscosity approximation methods for equilibrium problems and fixed point problems in Hilbert spaces. J. Math. Anal. Appl. 331, 506-515 (2007)

3. Plubtieng, S, Punpaeng, R: A general iterative method for equilibrium problems and fixed point problems in Hilbert spaces. J. Math. Anal. Appl. 336, 455-469 (2007)

4. Ceng, LC, Yao, JC: Strong convergence theorems by a relaxed extragradient method for a general system of variational inequalities. Math. Methods Oper. Res. 67, 375-390 (2008)

5. Moudafi, A: Viscosity approximation methods for fixed-points problems. J. Math. Anal. Appl. 241, 46-55 (2000)

6. Xu, HK: Viscosity approximation methods for nonexpansive mappings. J. Math. Anal. Appl. 298, 279-291 (2004)

7. Marino, G, Xu, HK: A general iterative method for nonexpansive mapping in Hilbert spaces. J. Math. Anal. Appl. 318, 43-52 (2006)

8. Takahashi, W: Weak and strong convergence theorems for families of nonexpansive mappings and their applications. Ann. Univ. Mariae Curie-SkTodowska, Sect. A 51, 277-292 (1997)

9. Shimoji, K, Takahashi, W: Strong convergence to common fixed points of infinite nonexpansive mapping and applications. Taiwan. J. Math. 5, 387-404 (2001)

10. Yao, Y, Liou, YC, Yao, JC: Convergence theorem for equilibrium problems and fixed point problems of infinite family of nonexpansive mappings. Fixed Point Theory Appl. 2007, Article ID 064363 (2007). doi:10.1155/2007/64363

11. Chen, R: Iterative schemes for fixed point computation of nonexpansive mappings. Abstr. Appl. Anal. 2012, Article ID 469270 (2012). doi:10.1155/2012/469270

12. Opial, Z: Weak convergence of the sequence of successive approximations for nonexpansive mappings. Bull. Am. Math. Soc. 73, 595-597 (1967)

13. Suzuki, T: Strong convergence of Krasnoselskii and Mann's type sequences for one-parameter nonexpansive semigroups without Bochner integrals. J. Math. Anal. Appl. 305, 227-239 (2005)

14. Combettes, PL, Hirstoaga, SA: Equilibrium programming in Hilbert space. J. Nonlinear Convex Anal. 6, 117-136 (2005)

15. Chang, SS, Joseph Lee, HW, Chan, CK: A new method for solving equilibrium problem fixed point problem and variational inequality problem with application to optimization. Nonlinear Anal. 70, 3307-3319 (2009) 